\title{
O poder de uma educação libertária na derribada de paradigmas repressivos: contribuições marxistas para a emancipação do trabalhador
}

The power of libertary education in the fall of repressive paradigms:
marxist contributions to workers emancipation

DÉBora de Jesus REZENDE BARCELOS

Pontifícia Universidade Católica de Minas Gerais

Carolina de Souza Novaes Gomes Teixeira

Pontifícia Universidade Católica de Minas Gerais.

Scarlat Horrara Rocha

Pontifícia Universidade Católica de Minas Gerais.

RESUMo O presente ensaio busca na educação um antídoto contra o retrocesso do Direito do Trabalho. Para tanto, parte de uma série de reflexões marxistas de cunho educacional que encontram na educação libertária uma maneira de emancipar o trabalhador e retirá-lo dos grilhões da alienação mediante métodos que propiciem a recuperação da até então perdida consciência de classe, bem como, a formação de um olhar crítico sobre a atual organização societária e a reconscientização do poder de luta do explorado para garantir melhores condições de labor e de vida. A fim de alcançar esses e outros objetivos, o método utilizado passará pela técnica da pesquisa histórica associada ao uso de material doutrinário e outros modos de levantamento bibliográfico.

Palavras-chave: Capitalismo. Trabalho. Alienação. Educação.

ABSTRaCr This essay seeks in education an antidote against the setback of labor law. To this end, it starts from a series of Marxist educational reflections that find in libertarian education a way to emancipate the worker and remove him from the shackles of alienation through methods that enable the recovery of the previously lost class consciousness, as well as the formation from a critical look at the current corporate organization and the awareness of the exploited's fighting power to ensure better working and living conditions. In order to achieve these and other objectives, the method used will be the historical research technique associated with the use of doctrinal material and other forms of bibliographic survey. Keywords: Caitalism. Work. Alienation. Education. 


\section{INTRODUÇão}

O homem difere dos animais pela necessidade de se reinventar, refazer e transformar, sendo assim, o trabalho é a mediação do homem com seu ambiente natural, formando a base da sociedade. Nas palavras de Marx citado por Giddens (2000, p. 49), "a totalidade daquilo que damos o nome de história universal não é senão a história de criação do homem pelo trabalho humano".

Dessa maneira, o processo histórico de transição do sistema feudal para o capitalismo foi marcado por duas fases relevantes, a primeira foi a ruína, total ou parcial das atividades feudais que ficavam a cargo do produtor, e a segunda consiste na separação do produtor dos meios de produção, por conseguinte, perdendo o controle do seu produto. É nesse momento que o trabalhador vende sua força de trabalho e se torna um ser alienado.

Nesse contexto, a organização econômica da sociedade prestigia determinadas classes, as quais detêm a propriedade do capital e os instrumentos de produção, sujeitando as demais à dominação e exploração. A alienação do trabalhador emana de uma produção cada vez mais exigente e inflexível, bem como, da ausência de controle dos objetos pelo trabalhador. Desse modo, uma demonstração da alienação acontece quando o produto é enfrentado pelo trabalhador como algo estranho e distante dele.

Nessa esteira, cabe salientar que o trabalhador não é beneficiado por aquilo que produz, o resultado é sempre apoderado pelo capitalista que criará as condições necessárias para concretização da propriedade privada. Ressalta-se que o obreiro nesse processo é coisificado, de modo que chega a assumir a condição de objeto aos olhos daquele que o emprega, objeto esse tanto mais vantajoso para o capital se comparado com aquele que efetivamente produz e comercia, pois a diferença da produção do trabalhador e do salário que ele recebe revela um lucro inestimável para o capitalista.

Para a economia política que, ao menos teoricamente haveria de ter um intuito moderador, a figura do trabalhador desempregado é, no entanto, completamente ignorada, pressupondo, assim, que para se enquadrar na sociedade cada pessoa deve exercer alguma atividade produtiva, de modo que aqueles sujeitos que não contribuem para a afirmação do capital tornam-se socialmente inexistentes. Nessa acepção, Giddens (2000) lembra que é a existência social que determina a consciência dos homens, sendo a exclusão social e a quebra de identidade de classe um dos pressupostos necessários à alienação e domesticação do trabalhador.

Fato é que quanto mais o capitalismo progride, tanto mais pobres se tornam os trabalhadores. Feita essa observação, um dos grandes sistemas que lamentavelmente têm sido usados a fim de legitimar e concretizar a classe dominante é o poder legislativo, cuja representação social tem sido totalmente desequilibrada à medida que se mostra majoritariamente composto por detentores de capital. Um exemplo de produto dessas e de outras mazelas é a Reforma Trabalhista, Lei 13.467/2017, que restou por recuar e mitigar em grande parte os direitos trabalhistas arduamente alcançados pelos obreiros.

Frente ao problema explanado, a educação emerge como sendo o recurso mais importante na luta de classes, dado que ela retira o trabalhador da condição de alienado, fazendo que ele tenha mais autonomia e reconquiste o status de cidadão, com o pleno gozo de seus direitos. 
Contudo, a educação pode apontar dois caminhos, sendo a educação libertária, ou a contenciosa, a primeira, que tem o condão de estimular o pensamento e a visão crítica proporcionando a emancipação, já a última é considerada um instrumento das classes que comandam, pela permanente manutenção de seu domínio sobre os demais. No decorrer do trabalho será feita uma exposição do capital e das implicações que esse sistema de produção requer, entre estes a alienação de seus empregados. A seguir, a educação será apresentada em suas diferentes facetas, a fim de se chegar a um modelo educacional que efetivamente contribua para a emancipação do trabalhador dos grilhões capitalistas, conferindo ao obreiro o poder de refletir e agir contra a supressão de seus direitos.

\section{2. "O CAPITAL"}

A palavra capital vem do latim capitale, derivado de capitalis, que vem do protoindo-europeu "kaput", significando "cabeça". O termo surgiu em referência às cabeças de gado, como era medida a riqueza em tempos antigos, mas também se relacionava à cabeça em seu sentido racional, enquanto parte superior do corpo e que comanda as outras. Embora tenha sido com frequência usada ao longo da história simbolizando acúmulo de dinheiro e riquezas, somente na modernidade a expressão passou a fazer referência a todo um sistema econômico de produção, momento em que lhe foi atribuído o sufixo "ismo", que indica a incidência de um excesso, dando origem à palavra "capitalismo". (D'ONOFRIO, 2012).

Partindo de um conceito simplificado exibido por Luc Boltanski e Ève Chiapello (2009) por capitalismo, como se apresenta hoje, podemos entender um processo econômico ancorado na exigência de acumulação contínua de capital (dinheiro) por meios formalmente específicos. Em outras palavras, trata-se de um procedimento no qual se requer o perpétuo investimento no circuito de mercado com o objetivo de extrair lucro que será novamente reinvestido, tendo em vista a obtenção de um lucro ainda maior.

A estrutura da sociedade capitalista surgiu da sociedade feudal, cuja dissolução gerou os elementos da primeira. Apesar de certas vertentes justificarem a origem do capitalismo enquanto o acúmulo de riquezas em decorrência da virtude de uns contraposta à incúria de outros, Marx (2011a) aponta a causa e razão primeva da inauguração das relações capitalistas enquanto o processo de separação entre o trabalhador e a propriedade das condições de realização de seu trabalho. Em suas palavras:

[...] o movimento histórico que transforma os produtores em trabalhadores assalariados aparece, por um lado, como a libertação desses trabalhadores da servidão e da coação corporativa. [...]. Por outro lado, no entanto, esses recém-libertados só se convertem em vendedores de si mesmos depois de lhe terem sido roubados todos os seus meios de produção, assim como todas as garantias de existência que as velhas instituições feudais lhes ofereciam (MARX, 2011a, p. 962).

Nesse cenário, os pretensos capitalistas trataram de deslocar não apenas os mestres artesãos corporativos, mas também os senhores feudais, uma vez que detinham as fontes de riqueza. Tal expropriação não foi, contudo, uma luta pacífica, mas gravada a sangue e fogo nos traços da humanidade (MARX, 2011a). 
Sob esse aspecto, Marx (2011a) assinala que a ascensão do capital se apresenta como fruto de uma luta vitoriosa contra o poder feudal e seus privilégios revoltantes, assim como contra as corporações e os entraves que colocavam a exploração do homem pelo homem.

Assim, com a dissolução dos séquitos feudais e a transformação das terras de lavoura em terras de pastagens de ovelhas pela nobreza remanescente, uma grande massa de antigos camponeses foi posta às ruas, despossuída de quaisquer meios de produção e, portanto, detentora unicamente de sua força de trabalho para viver (MARX, 2011a).

Era o nascimento do trabalhador assalariado, notadamente subjugado pela ordem capitalista, posto que dependia daquele emprego para manter-se.

Nesse contexto, valendo-se da necessidade existencial do trabalhador, o capital elevou a exploração de tal forma, que mulheres e crianças passaram a assumir trabalhos pesados, com salários aviltantes e jornadas extremamente dilatadas, sem qualquer descanso, seja diário, semanal ou anual. Os riscos à saúde e à integridade física dos trabalhadores também se tornaram corriqueiros, como escreveu Edward Palmer Thompson sobre os obreiros naquela época:

Um operário pode ser facilmente reconhecido quando caminha pelas ruas. Algumas de suas juntas provavelmente estarão afetadas. Se as suas pernas não forem tortas, terá os tornozelos inchados ou um ombro mais baixo que outro, ou os ombros projetados para frente. Ou qualquer outra deformação (THOMPSON apud NASCIMENTO; VIEGAS, 2016, p. 109).

É que a luta da burguesia ascendente contra os privilégios e as iniquidades tiranas nunca foi na verdade em favor dos oprimidos, mas tão-somente com fulcro em benesses próprias, benesses essas cujo alcance e manutenção dependeriam de uma série de atrocidades que em pouco se diferenciavam dos antigos modos, senão, para pior, mas que ainda assim assumiram o risco de cometer, passando-se seja lá sobre o que quer que fosse para chegar a seus fins, inclusive sobre as pessoas.

Nesse cenário, mortes por exaustão nos locais de trabalho eram cada vez mais corriqueiras entre homens e mulheres, quando não em crianças, que incapacitadas de gerir adequadamente as máquinas acabavam por sofrer trágicos acidentes de trabalho.

Essas e outras consequências nocivas promovidas pelo capital fomentaram o surgimento da crítica ao capitalismo. De acordo com Boltanski e Chiapello (2009), a crítica ao capitalismo pode se dividir em crítica estética e crítica social. A primeira, inspira-se no capitalismo enquanto fonte de desencanto e de inautenticidade dos objetos e das pessoas a quem lhe estão afetos, assim como, enquanto fonte de opressão, sob o argumento de que se opõe à liberdade, à autonomia e à criatividade dos seres humanos. Já a segunda crítica, por sua vez, faz referência ao egoísmo dos interesses particulares na sociedade burguesa e à miséria crescente das classes populares em uma sociedade altamente rica. Tal classificação é de suma importância, uma vez que tais críticas chegaram a ameaçar significativamente a perpetuidade do sistema, o que inaugurou a urgência de se atribuir um espírito ao capitalismo enquanto instrumento de legitimação e sobrevivência do modelo.

Com efeito, as pessoas precisavam de poderosas razões morais para se aliarem à organização econômica de capital. Assim, o espírito do capitalismo cingiu-se do discurso do 
progresso material, da eficácia e eficiência na satisfação da necessidade dos consumidores e do modo de composição social favorável ao exercício das liberdades civis para enaltecer um suposto bem comum providenciado pelo sistema (BOLTANSKI; CHIAPELLO, 2009).

Convém dizer inclusive que, especialmente, essa concepção de que a busca do interesse individual serve ao interesse geral foi objeto de um longo trabalho, incessantemente, retomado ao longo da história da economia clássica. A incorporação do utilitarismo à economia possibilitou considerar como ponto pacífico que "tudo o que é benéfico ao indivíduo é benéfico à sociedade". Boltanski e Chiapello $(2009$, p. 44) ensinam que "essa cartilha possibilita associar, de maneira ao mesmo tempo estrita e suficientemente vaga, lucro individual (ou local) e benefício global, para evitar a exigência de justificação das ações que concorrem para a acumulação".

No entanto, as injunções sistêmicas de bem comum, por si sós, não bastaram para alcançar o apoio social ao capitalismo. Era preciso que tal injunção fosse interiorizada junto à psiquê dos indivíduos, e isso, aliás, foi o papel da ideologia (BOLTANSKI; CHIAPELLO, 2009).

De fato:

[...] o espírito do capitalismo é justamente o conjunto de crenças associadas à ordem capitalista que contribuem para justificar e sustentar essa ordem, legitimando os modos de ação e as disposições coerentes com ela. Essas justificações, sejam elas gerais ou práticas, locais ou globais, expressas em termos de virtude ou em termos de justiça, dão respaldo ao cumprimento de tarefas mais ou menos penosas e, de modo mais geral, à adesão a um estilo de vida, em sentido favorável à ordem capitalista (BOLTANSKI; CHIAPELLO, 2009, p. 42).

Nisso reside a principal incumbência do capital para garantir a sua manutenção e legitimação ao longo do tempo, formar a consciência dos indivíduos de modo a aquiescer com os seus ditames, a fim de enfraquecer a crítica capaz de contê-lo e defrontá-lo, para que, assim, finalmente se alcance um verdadeiro estado de laissez-faire laissez-passer.

Nesse sentido, o capitalismo precisa ser apresentado aos futuros trabalhadores enquanto um modo de produção estimulante, capaz de oferecer possibilidades de autorrealização e liberdade de ação. A proposta esconde, no entanto, a realidade fundada na exclusão dos indivíduos ou grupos que não dispõem dos recursos financeiros necessários para aproveitar tais possibilidades (BOLTANSKI; CHIAPELLO, 2009).

Em outras palavras, trata-se de um autêntico processo de alienação e domesticação das grandes massas sociais, moldando-as em conformidade com os pressupostos que se deseja para que permaneçam resignadas à arbitrariedade e exploração próprias do sistema, consagrando-o no tempo e no espaço sem qualquer objeção.

\section{AlienaÇão: UM PRESSUPOSTO CRUCIAL}

Como visto, a alienação do homem que trabalha é requisito essencial de existência da ordem capitalista, sem o qual o capital não pode se manter, ao menos, não nos parâmetros desejados. 
Em termos gerais, pode-se dizer que a alienação do trabalhador veio para afastá-lo de si mesmo e dos outros homens, à medida que corpo, mente e convívio social lhe são afastados. Para Marx (1989), essa alienação ocorre em três aspectos, o primeiro deles, se refere à alienação do trabalhador com o resultado e o produto do seu trabalho, que se tornam objetos estranhos e alheios a ele. Em um segundo aspecto, no entanto, a alienação se manifesta na atividade produtiva, onde o trabalhador desgasta carne e ossos no desprendimento de sua força de trabalho. Nessa ocasião, o próprio trabalhador se exterioriza, se objetiva e se coisifica decaindo à condição da mais miserável mercadoria de todas, ao passo que a atividade que desempenha não é sua própria, mas de outro, o que equivale à perda de si mesmo (MARX, 1989).

Já o terceiro aspecto, por sua vez, se revela na autodeterminação do trabalhador. Aqui, o homem é privado de seu próprio gênero, que o difere de outras tantas espécies, ou seja, de sua atividade vital como uma atividade consciente, livre e universal, uma vez que a própria mente passa a ser programada para atender interesses contrários à sua individualidade (MARX, 1989).

Além de toda essa conceituação muito bem elaborada pelo autor, convém ressaltar, todavia, que a alienação não se restringe somente à formação de um psicológico passivo aos ultrajes condicionados pelo capital no decorrer de sua gênese, mas também, está direcionada à expansão do mercado, mediante uma dinâmica criadora de consciência e necessidades voltadas ao consumo.

Desta feita, pode-se dizer que enclausurado pela forma econômica do material, o imaterial é produzido, a consciência é erigida como ideologia, como falsa consciência, como pseudoformação (SILVA, 2005).

Marilena Chauí (2008) esclarece que, em sociedades divididas em classes, nas quais uma das classes explora e domina as outras, inúmeras explicações são produzidas e difundidas para justificar e legitimar seu poder econômico, social e político. Tais ideias ou representações tendem, por natureza, a esconder dos homens o modo real como suas relações sociais foram produzidas e a origem das formas sociais de exploração econômica e de dominação política.

Assim, sabido que a formação do psicológico dos sujeitos, conforme ensina Bissoli (2014), começa desde a infância, a construção desse caráter alienado não poderia se dar de outra forma, senão pelas vias da educação.

Com efeito, antigamente, a educação existia principalmente para a sobrevivência, no entanto, com o passar do tempo, as pessoas começaram a usar a educação para uma variedade de funções. A título de exemplo, o advento da Revolução Industrial gerou a necessidade de enviar crianças à escola para que se tornassem aptas a produzir e a se movimentar na sociedade. Cumpre destacar, não obstante, que essa necessidade não se deu pelo simples desejo de ter crianças mais cultas e instruídas, mas sim, para aprender o conhecimento adequado ao sistema produtivo (OLIVEIRA, 2009).

A esse respeito, já dizia A. Smith, citado por Marx (2011b), que a educação serviria a evitar tão e unicamente a degeneração completa da sociedade, de modo que o ensino popular a cargo do Estado não deveria ir além de doses cautelosamente homeopáticas.

Dessa forma, o capital tratou de ocupar a mente dos trabalhadores e de seus filhos com conteúdos pragmáticos, que não fomentam a discussão ou a reflexão, mas tão-somente 
se manifestam como dados objetivos e inquestionáveis no intuito de formar verdadeiras máquinas, despojadas de qualquer caráter questionador e, portanto, perfeitas ao sistema de opressão. Essa é a formação almejada pelas empresas que anunciam as tão escassas vagas de emprego: indivíduos polivalentes que atendam às demandas específicas da empresa em um dado momento, proativos e que se identifiquem com a empresa. Nesse viés, o empregado desejado deve trabalhar como se a empresa fosse sua, em outras palavras, trata-se de transformar o empregado, também, em um capitalista. Todavia, um capitalista controlado, que trabalha para além de todos os seus superiores.

Diante disso, resta-se evidente que a lógica da educação no capitalismo, ao naturalizar em seu interior os ditames da opressão e desigualdade, é voltada estritamente à produção, ao lucro e à consecução de interesses de uma classe predeterminada: a burguesia (OLIVEIRA, 2009).

No Brasil, não é diferente, segundo Maria Suzie de Oliveira (2009, p. 210), o atual sistema educativo "[...] vem confirmando o que se diz sobre a reprodução, exclusão e dominação. Projetos político-pedagógicos até existem e são propostos, mas são postos em andamento aqueles que legitimam o sistema e não representam para ele uma ameaça". Exemplo disso é o Projeto de Lei no. 867, de 2015, que propõe o programa Escola Sem Partido a fim de acabar com a suposta "doutrinação política e ideológica nas escolas", punindo os professores que porventura vierem a expressar opiniões contrárias ao pensamento da hegemonia.

Como se vê, a educação e a escola mantida pelo Estado, não interessa formar indivíduos capazes de desestabilizar ou questionar a ordem vigente, mas sim, obter consensos para a manutenção do sistema. Para tanto, até mesmo os espaços escolares sofreram interferências na sua forma de organização e de ensino. Segundo Santos, citado por Aryanne Martins Oliveira e Savana Diniz Gomes Melo (2016, p. 9):

[...] os parâmetros sugeridos nas esferas de produção estendem-se agora, aos sistemas escolares. A racionalidade do capital, presente nas escolas e em seus instrumentos cria uma hierarquia entre os conteúdos e habilidades que o aluno deve desenvolver.

De fato, disciplinas estáticas como a matemática e a linguística possuem uma carga horária muito maior que disciplinas que promovem a discussão e a meditação, entre elas a filosofia e a sociologia. O intento é justamente manter os alunos ocupados em matérias exatas para que não percebam as contradições do capital e não contestem a barbárie.

Nesse contexto, até mesmo o modelo de avaliações se torna um dos eixos prioritários na conformação do mercado educacional. De acordo com Oliveira e Melo (2016), tais avaliações servem de instrumento de homogeneização e de verificação das exigências demandadas na formação do trabalhador, além de atuarem também como elemento segregador, uma vez que permitem a comparação dos resultados sem uma análise social dos mesmos. Segundo as autoras, essas avaliações, à medida que controlam os resultados de aprendizagem dos estudantes, limitam e controlam igualmente o trabalho dos professores aos parâmetros exigidos.

Ademais, concomitantemente ao processo de obstrução dos alunos, os educadores, principalmente do ensino básico, acabam por sofrer inevitavelmente um processo de pro- 
letarização, haja vista a contínua precarização de suas condições de trabalho associada à perda do prestígio social. No caso brasileiro em especial, a proletarização do professorado não significou apenas seu empobrecimento econômico, mas também a depauperação do próprio acervo intelectual que a antiga categoria possuía (OLIVEIRA; MELO, 2016).

Tamanha é a alienação difundida nas escolas que os próprios conceitos de cidadania e democracia foram distorcidos. No modo de produção capitalista " [...] a apropriação aparece como alienação, como a exteriorização, e a exteriorização como apropriação, a alienação como a verdadeira cidadanização" (MARX, 1989, p. 163).

Efetivamente, a Política Econômica do capital impôs um discurso segundo o qual a alienação da força de trabalho é condição necessária para a aquisição do título de cidadão - "sich einburguern" (de "Burger" = cidadão) empregado no escrito original significa coloquialmente "aclimatar-se", ser aceito como habitual, devendo adequar-se ao sistema para adquirir direitos e foros (MARX, 1989).

Nesse sentido, o trabalhador fica adstrito a um solo social que o constrange e aprisiona, colocando obstáculos ao desenvolvimento de sua personalidade, qualidades e atividades, de modo que, aquele que não se torna mais um servo do produto, é tido como delinquente, vadio, marginal, e tão logo é excluído e descartado nas instituições penais.

No entanto, não é esse o verdadeiro significado do termo cidadania. Thomas Marshall (1967) ensina que o conceito de cidadania pode ser dividido em três aspectos: civil político e social. Nesse ínterim, o elemento civil se manifesta composto dos direitos necessários à liberdade individual - liberdade de ir e vir, de imprensa, de pensamento, de fé, o direito à propriedade e à contratação, entre outros. - Já o elemento político, mais comumente conhecido do termo, é aquele que efetivamente se refere ao direito de votar e ser votado, embora frisa-se, não seja o único como a grande maioria das pessoas acredita. Por fim, o elemento social também integra a concepção de cidadania, e por ele pode-se compreender tudo o que vai desde o direito a um mínimo de bem-estar econômico, até uma existência digna.

Desta feita, observa-se que somente a reunião desses três elementos é capaz de formar um verdadeiro cidadão, pleno em potencialidades e dignidade. Convém ressaltar que os aspectos civis e políticos são eficazmente garantidos no Estado Capitalista, contudo, o aspecto social é substancialmente ignorado. Ora, se o exercício de uma cidadania plena carece do uso e gozo de direitos sociais, e esses têm sido com frequência dilapidados com as "reformas", uma das principais particularidades que identificam o povo pertencente a determinado Estado civilizado vai se perdendo. Com isso, os indivíduos vão se estranhando perante os demais e perante o próprio Estado, rumo a um autêntico retorno à animalidade.

Com o conceito de democracia, não é diferente. A educação alienadora tem propagado um ensino que expõe a democracia como a legitimação dos Estados e seus regimes de governo, uma vez que a escolha dos governantes se dá pelo próprio povo. Contudo, democracia é muito mais que votar, e esse ato em si não garante para o votante a alcunha de cidadão, nem para o Estado a alcunha de democrático (SILVA; SILVA, 2012).

Segundo Kalina Silva e Maciel Henrique Silva (2012, p. 90-91), uma democracia efetiva: 
líticos não estivessem voltados para a satisfação das necessidades puramente materiais, mas que se preocupassem com a melhor forma de governo; em que a administração do que é público não estivesse nas mãos de 'cientistas' e 'técnicos', controlando de fora o que diz respeito aos cidadãos; em que o exercício da palavra e o exercício da ação não se contradissessem; em que as leis pudessem coincidir com os anseios dos destinatários; uma sociedade, enfim, em que as pessoas tivessem o sentido de comunidade a inspirar suas ações.

Esses e outros fatores de alienação contribuem significativamente para o enfraquecimento da crítica e das barreiras de resistência existentes entre os trabalhadores, já que acabam por gerar a aceitação popular da exploração e opressão promovidas pelo capital sob o discurso de que favorecem, também, o povo que trabalha.

Valendo-se dessa situação, obviamente o poder hegemônico encontrou desde logo uma forma sutil de derrocar os direitos trabalhistas duramente conquistados ao longo dos anos graças ao poder daquela mesma crítica, agora enfraquecida. São os chamados imperativos de flexibilização.

Maurício Godinho Delgado (2016, p. 67) define a flexibilização trabalhista como:

[...] a possibilidade jurídica, estipulada por norma estatal ou por norma coletiva negociada, de atenuação da força imperativa das normas componentes do Direito do Trabalho, de modo a mitigar a amplitude de seus comandos e/ou os parâmetros próprios para a sua incidência. Ou seja, trata-se da diminuição da imperatividade das normas justrabalhistas ou da amplitude de seus efeitos, em conformidade com autorização fixada por norma heterônoma estatal ou por norma coletiva negociada.

Nessa conjuntura a Lei 13.467/2017, comumente denominada Reforma Trabalhista, é exaustivamente aclamada pelos neoliberais como solução ao problema do desemprego e à derrocada da atual crise econômica. Tal reforma legislativa, contudo, traz em seu bojo inúmeras matérias que representam uma das mais ousadas formas de retrocesso efetivadas até então. Entre elas, a regulamentação do trabalho autônomo e intermitente, a prevalência do negociado sobre o legislado, banco de horas via contrato individual, supressão das horas in itinere e gravidez em local de trabalho insalubre.

Com efeito, os parcos direitos trabalhistas conquistados vão sendo suprimidos em nome do progresso, mas na verdade, estamos diante de uma revolução conservadora que restabelece a velha ordem na qual a última palavra é a do patrão (RUDIGER, 2004).

O Direito do trabalho passa a proteger o capital, e não o trabalhador, pois se torna, em última análise, um meio para amenizar ou eliminar, por meio da negociação as dificuldades enfrentadas pelas empresas (RUDIGER, 2004).

Embora seja sabido que a função do direito do trabalho nunca residiu unicamente na proteção do trabalhador, mas também na garantia de sobrevivência do capital, a essência desse ramo do direito - proteção dos trabalhadores e melhoria das condições de trabalho - é descaracterizada (RUDIGER, 2004). " [...] O novo modelo não quer exatamente o fim, mas o avesso do direito do trabalho" (VIANA, 2004, p. 182). 
E o mais interessante em meio a tudo isso é que o "povo" permanece completamente resignado, graças a essa discutida conjuntura social de alienação formada na psiquê dos indivíduos que os despoja de todo e qualquer pensamento crítico racional e, por conseguinte, os leva a contemplar a realidade que lhes defronta tal como efetivamente se apresenta, sem qualquer questionamento ou análise aprofundada. Assim, para os trabalhadores imersos nesse contexto, o retorno à barbárie constitui muitas vezes um fato inevitável, natural e até mesmo justificado, pelo qual não vale a pena lutar, o que evidencia ainda mais o caráter de conformismo e subordinação imposto pelo sistema.

Diante desse contexto de calamidade social, convém a nós perquirir acerca de quais seriam hoje, as possibilidades de recobrar-se a crítica e a resistência com suficiente confiança não só para conter o retrocesso, mas também para impor limites ao desenvolvimento de um capitalismo destrutivo (BOLTANSKI; CHIAPELLO, 2009).

Como demonstrado, a cidadania e a democracia acham-se em um regime aberto, incompleto e imperfeito, mas carregam em si um projeto em potencial, onde é possível construir novas formas de sociabilidade mais justas e igualitárias (SILVA; SILVA, 2012).

Para tanto, é necessário que o trabalhador seja, antes de tudo, emancipado da hodierna doutrina que o submerge no mar da resignação. Mas como emancipá-lo dos grilhões da alienação que o confinam à exploração?

Diante disso, é mister dizer que da mesma forma que a educação aliena, ela também pode emancipar, promovendo o retorno da crítica por meio da conscientização dos indivíduos enquanto agentes sociais de resistência à opressão imposta.

Mas que tipo de educação seria essa? Visto que o homem é educado em conformidade com o modo de produção vigente? Certo é que a educação capitalista não poderia deixar de produzir e formar alienação. Até mesmo porque o professor é também um empregado daqueles que desejam manter a sociedade em seu status quo e, portanto, não poderia deixar de fazer de seus alunos meros produtos capitalistas.

De fato, uma educação verdadeiramente emancipadora, capaz de conduzir os trabalhadores ao exercício de uma cidadania plena e à efetividade de um Estado Democrático de Direito não se encontra inserida nos padrões socialmente impostos que proíbem discussões questionadoras nas escolas sob o argumento de que se tratam de "atividades propriamente ideológicas e disseminadoras de ódio". A educação libertária, ao contrário, atua de modo a fomentar e a possibilitar aos futuros trabalhadores amplo acesso aos conhecimentos historicamente acumulados, de forma a permitir uma compreensão esclarecedora da sociedade, da cidadania e do modelo de produção existente como os são, produzindo a emancipação do homem que trabalha rumo a uma sociedade mais livre, justa e solidária, educação essa que se propõe expor a seguir.

\section{A educação Como antídoto ho Retrocesso}

Efetivamente, educar é um desafio social. Cada povo, cada cultura, apresenta sua educação. Assim sendo, ela pode ser imposta por um sistema centralizado de poder ou existir livremente entre os grupos. Quando tomada isoladamente, a prática educativa pode, 
como exposto alhures, assumir a forma de uma atividade alienante, mas ao mesmo tempo, se tomada de um ponto de vista emancipador, essa prática pode se tornar um instrumento mobilizador para com a situação atual em que vive a população, conferindo à humanidade a capacidade de dominar o seu próprio desenvolvimento, e assim, se libertar dos imperativos de retrocesso que conduzem à exploração.

Desta feita, embora a educação seja com frequência considerada como um elemento conservador da sociedade, por ser um instrumento formador e de expressividade em toda e qualquer organização social, ela não pode nem deve ser vista dentro de limites fechados (OLIVEIRA, 2009).

$$
\text { Segundo Marx (1999, p. 5): }
$$

[...] a teoria materialista de que os homens são produto das circunstâncias e da educação e de que, portanto, homens modificados são produtos de circunstâncias diferentes e de educação modificada esquece que as circunstancias são modificadas precisamente pelos homens e que o próprio educador precisa ser educado. Leva, pois, forçosamente, à divisão da sociedade em duas partes, uma das quais se sobrepõe à sociedade [...]. A coincidência da modificação das circunstancias e da atividade humana só pode ser apreendida e racionalmente compreendida como prática transformadora.

De fato, diferentes tipos de homem criam diferentes tipos de educação. Nesse cenário, a figura do educador aparece como um dos principais protagonistas da emancipação das classes oprimidas da dominação hegemônica.

Todavia, para promover uma educação voltada para uma sociedade em mudança, é necessário saber que se educa para a mudança, como processo e produto dela. Assim, somente quando os educadores se colocarem a refletir claramente sobre o que estão ensinando em um contexto maior de desenvolvimento individual e social o caminho para a emancipação se tornará possível (OLIVEIRA, 2009).

Segundo Maria Orlanda Pinassi (2009), reconhecer a grandeza da educação significa ter de enfrentá-la em sua imanência, enquanto esfera do conhecimento com historicidade, objetivos e ferramentas próprias. Mas, se o interesse for mais pretensioso e se quiser atingir patamares efetivamente emancipatórios, é necessário promover uma educação em caráter historicamente transcendente.

Portanto, a prática educativa não pode se resumir na instrução do indivíduo acerca de como desempenhar melhor os mesmos e antigos papéis, mas, sobretudo, deve estar pautada no desenvolvimento de novos papéis em uma sociedade que se renova, tornando os indivíduos os próprios "senhores" de seus destinos. Nesse sentido, é inegável que o professor emancipador deve ser um profissional competente e compromissado com o seu trabalho, que atue corajosamente na execução de seu ofício em conformidade com aquilo que acredita, suportando as consequências disso, e não mais aquele ser habilidoso para executar o que os outros concebem.

O ser humano precisa ser respeitado em sua totalidade, em suas potencialidades, modo de expressão e de pensar, ter o direito a uma educação igualitária e que reproduza a verdade, e não a uma reprodução maquiada da realidade histórica como educa o capital. É preciso uma educação democrática, que derrogue aquela fundada na escravidão. 
Nesse sentido, Marx (2011b) criticava a educação que transforma os alunos em produtos ou mercadorias que serão vendidas no mercado, criando categorias nas quais os educandos deveriam se enquadrar. Obviamente, essas categorias são meios pelos quais o capitalismo molda o trabalhador, preparando-o para suprir os anseios do mercado de trabalho. Em razão disso, Marx não via com bons olhos uma educação oferecida pelo Estado burguês, ao contrário, acreditava que as ideias até então passadas pela escola à classe dos trabalhadores destinavam-se a criar uma falsa consciência, que, por conseguinte, os impedia de perceber os reais interesses de sua classe (OLIVEIRA, 2009).

Desse modo, para Marx o ponto de partida inicial rumo ao reino da liberdade consiste essencialmente em uma prática educacional dedicada à formação de uma consciência crítico-libertária nos discentes, perante as condições concretas de alienação e exploração do trabalho. É necessário que eles, para que se autolibertem, adquiram antes certo grau de consciência histórica, isto é, a partir de fatos e acontecimentos concretos, para posteriormente questionar as estruturas e promover a mudança social. Nesse sentido, a utilização do materialismo histórico se mostra mais que pertinente (OLIVEIRA, 2004).

Segundo Engels citado por Marx (1989, p.112), por materialismo histórico pode-se entender:

[...] aquela concepção do curso da história que busca a causa última e a grande força que movimenta todos os eventos históricos importantes no desenvolvimento econômico da sociedade, nas transformações do modo de produção e de troca, na consequente divisão da sociedade em classes distintas e nas lutas dessas classes uma com a outra.

Sendo assim, apesar de não ter sido objeto de toda uma teoria educacional, o materialismo histórico constitui, sem dúvida, um método científico eficaz para compreender os acontecimentos do passado em sua essência verdadeira, uma vez que, em oposição aos métodos educacionais da burguesia, nos permite considerar o presente sob o ponto de vista da história e visualizar nela não somente a superfície, mas também as suas forças motrizes mais profundas, que, na realidade, são as responsáveis pelos atuais acontecimentos (LUKÁCS, 2003).

Por conseguinte, conforme observa Lukács (2003), o materialismo histórico tem para o proletariado um valor imensurável, posto que ultrapassa os limites de um método de ensino e assume a condição de um instrumento de luta, à medida que permite aos trabalhadores a compreensão da realidade social existente como verdadeiramente é, e assim, desmistifica a falsa ideologia que propaga a "fetichização da mercadoria" e a conformidade à exploração.

Não é sem razão que o aludido autor defende a adoção do materialismo histórico enquanto um método científico concreto, para além de sua rotulação como um simples programa que indica como a história deveria ser escrita, como ocorre atualmente no âmbito educacional (LUKÁCS, 2003).

Nesse contexto, Maria Orlanda Pinassi (2009, p. 97) instrui que, a luta contra o sistema de reprodução social do capital, 
tentativa de constituir interdisciplinaridades conexas. A questão é muito mais complexa e requer a perspectiva de uma qualidade ontológica socialmente diferenciada da produção de conhecimento, algo que só pode acontecer mediante a recomposição da autêntica totalidade, ou seja, da relação entre o universo conceitual e a concreta perspectiva sócio-histórica.

Marx realizou essa proeza de superar o dilema burguês que separa o idealismo do materialismo, a objetividade da subjetividade. Essa maturidade histórica e genialidade do autor são os ingredientes da bomba com base na qual afirma-se que, para os problemas concretos, as soluções devem ser igualmente concretas (PINASSI, 2009).

Corroborando com esse entendimento, Paulo Freire (1996) acredita que é pensando criticamente a prática de hoje, ou de ontem, que se pode melhorar a prática de amanhã. Nesse viés, destaca que o mundo não é, mas está sendo. Assim, compete aos sujeitos não apenas constatar o que ocorre, mas também intervir nas ocorrências, para mudá-las.

Partindo dessas premissas, preservar situações de miséria é, sem dúvida, uma imoralidade. A mudança se mostra difícil, mas é possível (FREIRE, 1996).

Não se trata obviamente de impor à população espoliada e sofrida que se rebele, que se mobilize, que se organize para defender-se, vale dizer, para mudar o mundo. Trata-se, na verdade, de desafiar os grupos populares para que percebam, em termos críticos, a violência e a profunda injustiça que caracterizam sua situação concreta. Mais ainda, que sua situação concreta não é destino certo ou vontade de Deus, algo que não possa ser mudado (FREIRE, 1996, p. 31).

Assim, o educador progressista não pode impor arrogantemente o seu conhecimento como o verdadeiro, mas fomentar o diálogo em que se vai instigando as massas populares a pensarem a sua história social como a experiência igualmente social de seus membros, somente assim, será possível superar certos saberes que, uma vez desnudados, se mostrarão incompetentes para explicar os fatos, evidenciando a perversidade e abrindo portas para a busca e implementação de um novo modelo socioeconômico (FREIRE, 1996).

Evidentemente, trata-se de um processo educacional cujos resultados serão obtidos a longo prazo, mas ainda assim, é preciso persistir. Se existe um dizer clichê que não pode ser ignorado, é o de que as crianças e jovens de hoje são o futuro do país amanhã, e temos de nos ater a isso. Com efeito, os educandos do tempo presente haverão de ser os principais agentes sociais do porvir, habilitados a direcionar a sociedade a uma ordem verdadeiramente progressista.

É forçoso lutar com as armas disponíveis em direção a uma sociedade que realmente promova a dignidade e a democracia, e, no momento, a melhor delas é o poder de uma educação que emancipa.

\section{DEMAIS PONDERAÇões MARXISTAS NO ÂMBITO DA EDUCAÇÃo}

Além da significativa contribuição de Marx, no tocante ao materialismo histórico, o autor também considerava ser necessária a associação entre conhecimento e experiência no âmbito educacional para que, enfim, a tão sonhada emancipação fosse conquistada pela classe trabalhadora. 
Com efeito, um dos objetivos da revolução defendida pelo autor era justamente promover o desenvolvimento integral dos trabalhadores em seu aspecto intelectual, físico e técnico. Para tanto, seria imprescindível aprender competências que seriam indispensáveis para a compreensão do mundo físico e social. Nessa direção, Marx propôs a conjugação entre ensino, trabalho e ginástica em suas Instruções aos Delegados do Conselho Central Provisório da Associação Internacional dos Trabalhadores em 1868.

[...] afirmamos que a sociedade não pode permitir que pais e patrões empreguem, no trabalho, crianças e adolescentes, a menos que se combine este trabalho produtivo com a educação.

Por educação entendemos três coisas:

1) Educação intelectual.

2) Educação corporal, tal como a que se consegue com os exercícios de ginástica militares.

3) Educação tecnológica, que recolhe os princípios gerais e de caráter científico de todo o processo de produção e, ao mesmo tempo, inicia as crianças e os adolescentes no manejo de ferramentas elementares dos diversos ramos industriais (MARX, 2011b, p. 85).

Partindo-se do pressuposto de que toda teoria social é filha de seu tempo, para compreender esse ponto temos que considerar o contexto histórico e social em que o pensamento de Marx foi concebido, a forma pela qual se compreendiam o trabalho e o ensino naquele momento e, mais ainda, a própria ideia de infância que se fazia em meados do século XIX, período de consolidação do capitalismo, subsequente à Revolução Industrial ocorrida na Inglaterra no século XVIII. Obviamente, tais preceitos sugeridos pelo autor não caberiam na atualidade, onde o trabalho infantil é crime e não pretendemos mudar isso.

Ainda assim, cumpre destacar que, embora Marx sustentasse a integração entre educação e trabalho desde a infância, isso não deve ser entendido como apologia à exploração do trabalho infantil, tais métodos, na verdade, segundo o filósofo, consubstanciavam-se em "antídotos absolutamente indispensáveis para resistir aos efeitos de um sistema social que degrada o operário até o ponto de transformá-lo em um simples instrumento de acumulação de capital" (MARX, 2011b, p. 84).

Nesse sentido, o primeiro ponto proposto por Marx nas Instruções aos Delegados, mais precisamente, àquele relativo à educação intelectual, se refere ao estudo dos conteúdos e da cultura em geral sob um viés questionador. Acredita-se que a razão da proposta tenha se dado junto ao objetivo de eliminar o aspecto do estranhamento do trabalhador perante o produto de seu trabalho, no qual não se reconhece, mas ao contrário, aparece como um objeto que o defronta exercendo poder e controle de modos elevados perante ele, que se vê diante de uma necessidade ilusória, mas, ao mesmo tempo, incontrolável de adquirir “seu” próprio produto. Com efeito, Marx já havia advertido desde os Manuscritos Econômico-Filosóficos (1844) que a valorização do mundo das coisas importaria na desvalorização das pessoas, logo, para que fosse promovida a revalorização do mundo dos homens, seria preciso a desmistificação do fetiche instaurado pelas mercadorias, o que só poderia se dar por meio da educação, esclarecendo os homens de que não passam de objetos criados por eles mesmos e que, portanto, não possuem a capacidade de rotulá-los como homens 
bem-sucedidos ou não, e muito menos, como pessoas dignas ou indignas de aproximação, embora assim discorra o capital, vale dizer, até os dias de hoje.

Outro ponto de alienação que a educação intelectual seria capaz de por si só elucidar consiste na autodeterminação do trabalhador. Vimos que, segundo Marx, o caráter edificante, socializante e humanizante do trabalho, onde o sujeito se constrói na relação com os demais sujeitos, desfez-se na sociedade capitalista de tal modo que o indivíduo privou-se de seu próprio gênero no instante em que deixou de exercer sua atividade produtiva de forma consciente, livre e universal.

Também aí a educação emanciparia, pois atuaria conscientizando o trabalhador e trazendo à memória a importância do trabalho como um fim e não como um meio de explorar e de permitir ser explorado.

A educação corporal, por sua vez, mostrava-se necessária visto que o labor para o sistema de capital, àquela época, usurpava não só o tempo para crescimento dos jovens e crianças, como também para o desenvolvimento e a manutenção sadia de seus corpos, atropelando os limites físicos da jornada de trabalho de modo a esgotar todo e qualquer momento que, em tese, deveria ser destinado para o preenchimento das funções sociais e o jogo livre das forças vitais. Mas, ao contrário, acabava por produzir a exaustão prematura e o aniquilamento da própria força de trabalho, o que demandou a imprescindibilidade de uma educação corporal, justamente para elevar a resistência física e as expectativas de vida daqueles que laboravam e ainda laboram em condições desgastantes de trabalho. É preciso salientar também que, no modo de produção capitalista, não é apenas o trabalhador que é desumanizado, mas também os proprietários dos meios de produção e é essa linha educacional que, inclusive, favorece também os últimos.

Conforme os dizeres de Marx (1989, p. 163-164), “o comportamento prático, efetivamente real do trabalhador na produção e para com o produto [...] aparece como comportamento teórico no não-trabalhador, que está frente àquele". Dessa forma, o corpo físico tanto do proletário como do "patrão" é sempre ignorado. Para o primeiro, quanto mais belo o fruto de seu trabalho, tanto mais mutilado o trabalhador, que depreende toda a sua força vital naquele ofício, mortificando sua physis. Já em relação ao segundo, ávido por sobressair na concorrência e pelo lucro máximo, olvida-se de si mesmo enquanto dono do saber diretivo teórico, desvanecendo em tal ocupação sedentária e, assim, deplora-se também sua própria natureza material - uns se exercitam de mais, outros, de menos.

Para solucionar esse problema, o marxismo opera com o princípio de que tanto o corpo como a mente do homem devem se desenvolver de forma simultânea, ou seja, o homem não é apenas materialidade corporal, ou, muito menos, se reduz à subjetividade adstrita (OLIVEIRA, 2009).

Por fim, a ideia de educação tecnológica vai ao encontro da necessidade de conhecimento dos procedimentos tecnológicos da totalidade da produção. A proposta consiste na união entre ensino e trabalho desde a infância, ficando as crianças parte do tempo na escola e parte no trabalho, mas não para que trabalhem de modo a aumentar a produtividade e o lucro da indústria e, sim, para que atinjam o desenvolvimento pleno de suas capacidades.

Igualmente aqui, a educação tecnológica também emanciparia o trabalhador, agora, sob a face daquele segundo aspecto da alienação conceituado por Marx no início do presen- 
te ensaio, mais precisamente, aquela relativa à atividade produtiva mesma, conferindo ao obreiro a oportunidade de abandonar o trabalho prestado a outrem e laborar para si mesmo.

De acordo com Manacorda (2007), a moderníssima ciência da tecnologia herdou a divisão do trabalho que persiste nas fábricas. O operário, então, torna-se cada vez mais parcial e supérfluo a toda e qualquer variação da base técnica da produção, de modo a se encontrar à mercê do velho meio de trabalho, que, uma vez alterado, dá cabo a toda a sua possibilidade de labor e de vida.

Assim, no intuito de retirar essa completa imprevisibilidade que assombra o trabalhador, Marx (2011b) recomendou a instrução tecnológica. Trata-se de fazer que os jovens percorram todo o sistema de produção para que sejam enfim libertos da subordinação a um só ramo produtivo. Efetivamente, uma das maiores preocupações de Marx era ir contra a tendência "profissionalizante" que levava as escolas a influenciar o exercício de determinada função. Defendia, pois, uma educação técnica e industrial, mas não um vocacionalismo estreito.

Nesse cenário, considerava que a conjugação entre ensino e trabalho seria eficaz para conferir ao indivíduo a execução e o gozo do próprio labor. Destarte, pressupunha que a adoção única do ensino teórico seria insuficiente para libertar o operário, visto que não lhe atribuiria a experiência prática necessária para realizar seu trabalho. Ao mesmo tempo, o saber prático não teria sentido algum sem a teoria, pois o trabalhador, nesse caso, continuaria a depender de outrem intelectualmente capacitado para coordenar seu trabalho.

Em suma, a educação associada ao trabalho produtivo, em Marx chamada educação politécnica, teria a função de reintegrar o trabalho intelectual ao trabalho manual, separados na sociedade capitalista. A intenção é que o trabalhador tenha uma compreensão integral do processo produtivo para se emancipar dele, em especial, de falsos estigmas de profissão.

Ademais, o ensino politécnico seria também uma forma de deixar o aluno mais tempo envolvido com sua educação, de modo a possibilitar o desenvolvimento integral de todos os seus sentidos e potencialidades.

No bojo dessa filosofia, a educação está associada ao conceito de omnilateralidade, cujo objeto consiste na produção de cultura e na construção de saberes em contraponto à formação unilateral do homem, assim compreendida enquanto aquela especializada e alienada que resulta da divisão do trabalho e da fragmentação de tarefas.

De acordo com Manacorda (2007), a figura da omnilateralidade pode ser definida como a existência de um desenvolvimento total, completo e multilateral das faculdades e das forças produtivas, das necessidades e da capacidade de sua satisfação. Homem omnilateral é, então, aquele que detém a plena posse de capacidades teóricas e práticas, não apenas para o trabalho, mas também para os prazeres humanos.

Essas disponibilidade e variabilidade já se encontravam no livro A Ideologia Alemã (1845-1846), quando Marx, por oposição a uma sociedade dividida, concebe uma sociedade em que não existam pintores, mas, no máximo, homens que também pintam (MARX, 2007).

Assim, como resultado de um processo de autocriação, o homem omnilateral se apresenta com uma totalidade de possibilidades. Com a exteriorização de suas faculdades criativas sem qualquer acondicionamento, o homem aparece universalmente disponível à atenção das exigências humanas, que se podem configurar no criar gado ou no cultivar lavoura, 
no exercício do estudo ou da produção. "Trabalho omnilateral e não-trabalho igualmente omnilateral como desenvolvimento das potências universais da mente, do cérebro humano: é esta a manifestação do homem" (MANACORDA, 2007, p. 92).

Além de todos os aspectos educacionais ora expostos, não se pode olvidar de mencionar que Marx também defendia uma educação pública, compulsória, gratuita e laica.

No entanto, embora advogasse uma educação custeada pelo Estado, Marx não admitia que o ensino viesse a sofrer qualquer influência dele, pelo fato de seus currículos e métodos de instrução representarem o conjunto das relações econômicas concretas da sociedade. Marx sugeria, portanto, que o governo nomeasse inspetores cuja função se resumiria a fiscalizar o cumprimento das leis nas escolas, sem que tivessem, todavia, o direito de intrometer-se diretamente no ensino.

A concepção educacional proposta por Marx em tudo quanto se mostra compatível com os preceitos atuais é de grande pertinência, em especial, quanto à promoção de uma conscientização crítico-libertária nos alunos por meio da adoção do materialismo histórico rumo à emancipação da falsa consciência criada pela teoria pedagógica liberal.

É preciso esclarecer aos futuros trabalhadores, desde a infância, os direitos que detêm e a razão histórica de tê-los alcançado para que a corriqueira prática usurpativa de carne e sangue dos obreiros não se perpetue no tempo. Ademais, o restabelecimento do vínculo de solidariedade perdido entre a população em virtude das malogradas relações de concorrência e de quebra de identidade profissional próprias do capital se revelam mais que necessário, vínculo esse que indubitavelmente se inicia nas escolas, entre os colegas de classe. Os educandos precisam não somente aprender, mas apreender a importância de seu posicionamento social e os reflexos positivos que podem advir de sua intervenção, obstando o retrocesso.

Por sua vez, por que não a implementação de uma educação politécnica para os jovens do ensino médio em conformidade com a legislação relativa à jornada de menores vigente? Efetivamente, tal vertente já tem sido observada em âmbito nacional sob o ângulo do ensino integral, um mecanismo eficaz merecedor de quanto mais investimentos.

Por todo o exposto, é passível de se afirmar que a proposta educacional de Marx recupera o sentido do trabalho enquanto atividade vital em que o homem humaniza-se ao invés de alienar-se, e nisso reside seu caráter progressista e emancipador, em uma educação que contempla o ser humano e sua dignidade como ponto de referência e não como um simples instrumento para a realização de interesses pessoais. Uma educação que apresenta aos alunos a necessidade crucial de se exercer um pensamento crítico-racional a fim de que cada um detenha a capacidade de se situar na sociedade na qual está inserido e modificá-la, para melhor, rumo a um elo social efetivamente calcado na justiça, na solidariedade, na dignidade e que derrogue a exploração.

\section{CONSIDERAÇÕES FINAIS}

É inegável que a educação desempenha um papel significativo na formação de cidadãos autônomos e críticos. Tomando por base o contexto social na relação de trabalho, 
é a partir da educação que o trabalhador consegue sua emancipação, ou seja, sair do domínio e coerção do outro.

Caso a prática pedagógica seja, no entanto, aplicada de forma errônea, de modo a delinear o consciente e instituir opinião por meio da imposição de uma ideologia cautelosamente elaborada por uma pequena parte da sociedade para atender a seus interesses, não serão alcançados os objetivos de uma construção humana libertadora que a educação tanto promete, mas antes, indivíduos alienados, completamente coisificados e prontos para atender ao comando alheio sem qualquer reflexão. Assim, o conteúdo aplicado tem uma grande parcela de responsabilidade pela modificação da consciência crédula para a crítica.

Pondera Marx que a educação está massificada, pois os ensinamentos são herdados das gerações precedentes, sendo que os educadores apenas continuam e complementam aquele processo de aprendizagem, não havendo para os aprendizes outro caminho, senão uma simples reprodução de conteúdo, o que obstrui a promoção dos sujeitos e o exercício da cidadania.

Esse tipo de educação supracitada que preza pelo controle social facilita a sujeição e a aceitação da exploração dos dominadores, por não assumir uma postura crítica, sendo predominante o conformismo na relação de trabalho.

Diante do exposto, a partir da educação libertária o trabalhador atinará para o que realmente acontece no mercado de trabalho, atuando com criticidade, permitindo o afastamento da condição exploratória e apropriando-se da realidade, conduzindo de forma consciente a capacidade produtiva. Por fim, o trabalhador se situará na esfera política com autorreconhecimento enquanto possuidor de direitos e não apenas de deveres, o que por conseguinte lhe proporcionará a capacidade de demandar e lutar por melhores condições de trabalho e de vida, para que finalmente se consagre a sua dignidade, não somente no plano simbólico, mas efetivo.

\section{REFERÊNCIAS}

BATISTA; Eraldo Leme; ORSO, Paulino José. Intensificação do trabalho, alienação e emancipação humana. In: XII Jornada do Histedbr. São Luís. A crise do capitalismo e seus impactos na educação pública brasileira. São Luís, 2014. Disponível em: http://www.histedbr.fe.unicamp.br/acer_histedbr/jornada/jornada12/artigos/3/artigo eixo3_99_1409754645.pdf. Acesso em: 30 ago. 2018.

BISSOLI, Michelle de Freitas. Desenvolvimento da personalidade da criança: o papel da educação infantil. Psicologia em Estudo. Maringá, v. 19, v. 4, p. 587-597, out-dez. 2014. Disponível em: <http://www.scielo.br/pdf/pe/v19n4/1413-7372-pe-19-04-00587.pdf>. Acesso em: $1^{\circ}$. set. 2018.

BOBBIO, Norberto. A Era dos Direitos. Rio de Janeiro: Campus, 1992. Capítulo que leva o nome do livro, p. 49-65. 
BOLTANSKI, Luc; CHIAPELLO, Ève. O novo espírito do capitalismo. Trad. Ivone C. Benedetti. São Paulo: Martins Fontes, 2009.

BRUNO, Lúcia. Educação e Trabalho no Capitalismo Contemporâneo. São Paulo: Atlas, 1996.

CATANI, Afrânio M. O que é Capitalismo. São Paulo: Brasiliense, 1999.

CHAUÍ, Marilena. Direitos Humanos e Medo. In: Ribeiro Fester, Antonio Carlos (Org.). Direitos Humanos e... São Paulo: Brasiliense, 1989, p. 15-35.

CHAUÍ, Marilena. O que é ideologia, 2. ed. São Paulo: Brasiliense, 2008.

DELGADO, Maurício Godinho. Curso de Direito do Trabalho, 15. ed. São Paulo: LTr, 2016.

D’ONOFRIO, Salvatore. Capitalismo. In: D'ONOFRIO, Salvatore. Capitalismo. Dicionário de Cultura Básica. [S.1.]. 2012. Disponível em: https://pt.wikisource.org/wiki/Dicion\%C3\%A1rio_de_Cultura_B\%C3\%A1sica/Capitalismo . Acesso em: 6 fev. 2019.

FREIRE, Paulo. Pedagogia da autonomia: saberes necessários à prática educativa. São Paulo: Paz e Terra, 1996.

GIDDENS, Anthony. Capitalismo e Moderna Teoria Social. Lisboa: Presença, 2000.

GOMES, Dinaura Godinho Pimentel. O princípio constitucional da dignidade da pessoa humana e a flexibilização da legislação trabalhista. Revista de Direito Constitucional e Internacional, São Paulo, v. 11, n. 44, p. 92-143, jul./set. 2003.

HEILBRONER, Robert L. A Natureza e a Lógica do Capitalismo. São Paulo: ÁTICA, 1985.

LUKÁCS, Georg. História e consciência de classe: estudos sobre a dialética marxista. Trad. Rodnei Nascimento. São Paulo: Martins Fontes, 2003.

MANACORDA, Mario Alighiero. Marx e a pedagogia moderna. Trad. Newton Ramos de Oliveira. Campinas: Alínea, 2007.

MARSHALL, Thomas H. Cidadania, Classe Social e Status. Rio de Janeiro: Zahar, 1967, p. 57-114.

MARX, Karl. Manuscritos Econômico-Filosóficos. Lisboa: Edições 70, 1964. 
MARX, Karl. O capital. Trad. Rubens Enderle. São Paulo: Boitempo, 2011a.

MARX, Karl. Sobre a questão judaica. Trad. Nélio Schneider, Daniel Bensaid e Wanda Caldeira Brant. São Paulo: Boitempo, 2010.

MARX, Karl. Teses sobre Feuerbach (1845). [S.1.]: Ridendo Castigat Mores, 1999. Disponível em: <http://www.ebooksbrasil.org/adobeebook/feuerbach.pdf>. Acesso em: 7 ago. 2018.

MARX, Karl. Trabalho alienado e superação positiva da auto-alienação humana. In: FERNANDES, Florestan, Marx e Engels. São Paulo: Ática, 1989.

MARX, Karl.; ENGELS, Friedrich. A ideologia alemã: crítica da mais recente filosofia alemã em seus representantes Feuerbach, B. Bauer e Stirner, e do socialismo alemão em seus diferentes profetas (1845-1846). Trad. Rubens Enderle, Nélio Schneider e Luciano Cavini Martorano. São Paulo: Boitempo, 2007.

MARX, Karl; ENGELS, Friedrich. Textos sobre educação e ensino. José Claudinei Lombardi. (Coord.). Campinas: Navegando, 2011b.

MATA, Vilson Aparecido da. Emancipação e educação em Marx: entre a emancipação política e a emancipação humana. In: V Encontro Brasileiro de Educação e Marxismo. 2011, Florianópolis. Anais... Florianópolis: Marxismo, Educação e Emancipação Humana, 2011, p. 1-17. Disponível em: http://www.nupemarx.ufpr.br/Trabalhos/Eventos/V\%20 EBEM/V_EBEM_MATA_Vilson_Emancipacao_e_educacao_em_Marx.pdf. Acesso em: 7 ago. 2018.

MÉSZÁROS, István. A educação para além do capital. Trad. Isa Tavares, 2. ed. São Paulo: Boitempo, 2008.

NASCIMENTO, Lauriene do; VIEGAS Cláudia Mara de Almeida. Flexibilização das normas trabalhistas como ônus da crise econômica: o trabalhador pagará a conta? Revista de Direito do Trabalho. São Paulo, v. 42, n. 170, p. 105-136, jul./ago. 2016.

OLIVEIRA, Aryanne Martins; MELO, Savana Diniz Gomes. O estado capitalista e o trabalho docente. In: I Simpósio Educação, Marxismo e Socialismo, 2016, Belo Horizonte. Anais... Belo Horizonte: Editora UFMG, 2016. Disponível em: <https://docs.wixstatic. com/ugd/ac5263_c793ac1587374fe19439a5c6e99186fe.pdf>. Acesso em: 5 set. 2018.

OLIVEIRA, Jorge Luís de. A superação do trabalho alienado como condição da emancipação humana em Marx, 2004, 216s. Dissertação (Mestrado em Filosofia) - Universidade Federal do Ceará, Programa de Pós-Graduação em Filosofia, Fortaleza. 
OLIVEIRA, Maria Suzie de. Algumas considerações sobre a educação concebida por Karl Marx. Educere et Educare Revista de Educação. Cascavel, v. 4, n. 8, p. 199-212, jul./ dez. 2009. Disponível em: <http://e-revista.unioeste.br/index.php/educereeteducare/article/view/2328>. Acesso em: 7 ago. 2018.

PINASSI, Maria Orlanda. Da miséria ideológica à crise do capital: uma reconciliação histórica. São Paulo: Boitempo, 2009.

ROSSI, Wagner Gonçalves. Capitalismo e Educação: Contribuição ao Estudo Crítico da Economia da Educação Capitalista. São Paulo: Cortez e Moraes, 1998.

RUDIGER, Susanne Dorothee. Teoria da flexibilização do Direito do Trabalho: uma tentativa de contextualização histórica. Prima@ Facie: Revista da Pós-Graduação em Ciências Jurídicas, João Pessoa, v. 3, n. 4, p. 29-57, jan./jun. 2004. Disponível em: <http://periodicos.ufpb.br/ojs/index.php/primafacie/article/view/ 4455>. Acesso em: 30 ago. 2017.

SANTIAGO, Theo. Do Feudalismo ao Capitalismo: uma discussão histórica, 5. ed. São Paulo: Contexto, 1999.

SAUL, Fernanda Quatorze Voltas. A educação no pensamento de Karl Marx. Revista Veras. São Paulo, v. 4, n. 1, p. 25-36, jan./jun. 2014. Disponível em: <http://site.veracruz. edu.br/instituto/revistaveras/index.php/revistaveras/article/view/145>. Acesso em: 7 ago. 2018.

SILVA, Cesar Augusto Alves da. Educação e não emancipação: os limites objetivos da educação escolar no capitalismo industrial contemporâneo. Revista Educação e Sociedade. Campinas, v. 39, n. 143, p. 439-454, jun. 2018. Disponível em: $<$ http:/www.scielo.br/scielo.php?script $=$ sci_arttext\&pid $=\mathrm{S} 0101-73302018000200439 \& \operatorname{lng}=\mathrm{en} \& \mathrm{nrm}=\mathrm{iso}>$. Acesso em: 5 set. 2018 .

SILVA, João Carlos da. Educação e alienação em Marx: contribuições teórico-metodológicas para pensar a história da educação. Revista Histedbr, Campinas, n. 19, p. 101-110, set. 2005. Disponível em: http://www.histedbr.fe.unicamp.br/revista/revis/revis19/art07_19. pdf. Acesso em: 30 ago. 2018.

SILVA, Kalina Vanderley; SILVA, Maciel Henrique. Dicionário de Conceitos Históricos, 4. ed. São Paulo: Contexto, 2012.

VIANA, Márcio Túlio. A proteção social do trabalhador no mundo globalizado - o direito do trabalho no limiar do século XXI. In: PIMENTA, José Roberto Freire et al. Direito do Trabalho: evolução, crise, perspectivas. São Paulo: LTr, 2004, p. 155-183. 


\section{DADOS DOS AUTORES}

\section{Débora de Jesus Rezende Barcelos}

Mestranda no Programa de Pós-graduação em Direito da Pontifícia Universidade Católica de Minas Gerais. Especialista em Direito do Trabalho e Previdenciário pela mesma instituição. Bacharel em Direito pela Faculdade Mineira de Direito da Pontifícia Universidade Católica de Minas Gerais (PUC Minas). deboradejesus.barcelos@gmail.com.

\section{Carolina de Souza Novaes Gomes Teixeira}

Doutora e mestre pela PUC - Minas. Graduação em Direito pela Universidade Federal de Ouro Preto (2011). Especialista em Direito Privado pela Universidade Cândido Mendes - RJ e em Direito da Propriedade Intelectual pela Justus Liebig Universitat - Giessen, Alemanha. Professora Adjunto I da Pontifícia Universidade Católica de Minas Gerais. carolinasnovaes@gmail.com.

\section{Scarlat Horrara Rocha}

Bacharel em Direito pela Pontifícia Universidade Católica de Minas Gerais. Advogada. shorrara@yahoo.com.br

Submetido em: 27-6-2020

Aceito em: $31-8-2020$ 